\title{
Post Prostatectomy Vesicourethral Stenosis or Bladder Neck Contracture with Concomitant Urinary Incontinence: Our Experience and Recommendations
}

\author{
Shieh L. Bang ${ }^{\mathrm{a}} \quad$ Sachin Yallappa $^{\mathrm{a}} \quad$ Fatima Dalal $^{\mathrm{a}} \quad$ Yahia Z. Almallah $^{\mathrm{b}}$ \\ aDepartment of Urology, The Queen Elizabeth Hospital, University Hospital Birmingham; bUniversity Hospital Birmingham, NHS \\ Foundation Trust, Birmingham, UK
}

\section{Key Words}

Bladder neck contracture $\cdot$ Prostatectomy • Incontinence •

Sling • Artificial urinary sphincter

\begin{abstract}
Objectives: To present our experience in the management of bladder neck contracture with concomitant post prostatectomy incontinence and to provide our recommendations based on the updated literature. Materials and Methods: Between Jan 2010 and June 2015, 37 patients from our cohort of 341 patients with post prostatectomy incontinence were evaluated. Patient data were retrospectively collected. Patients with bladder neck contracture confirmed on flexible cystoscopy underwent subsequent rigid cystoscopy and deep endoscopic bladder neck incision (BNI). A follow up flexible cystoscopy would be performed 3 months later. If there was no recurrence of the bladder neck contracture, an artificial urethral sphincter (AUS) or a male sling was recommended. Results: The mean age of patients was 68 years (range 59-77) and the mean BMI was 31 (range 21-41) kg/ $\mathrm{m}^{2}$. Twenty-five (67.7\%) patients had open prostatectomy and 12 (32.4\%) patients had laparoscopic prostatectomy. Fourteen patients $(37.8 \%)$ underwent adjuvant radiother-
\end{abstract}

(C) 2016 S. Karger AG, Basel

Fax +4161306 1234

E-Mail karger@karger.ch

www.karger.com

\section{KARGER}

Accessible online at: www.karger.com/cur apy. Twenty-four (64.8\%) patients had one BNI procedure, 8 (21.6\%) patients had two procedures and 5 (13.5\%) patients had more than 2 procedures. Twenty-one (91.3\%) patients had AUS implantation and 2 (8.7\%) patients had male sling placement. Besides, $85.7 \%$ of AUS and $50 \%$ of male sling patients managed to achieve successful outcomes with a mean follow up period of 13.1 months ( range 2-33 months). Conclusion: Initial management with aggressive BNI followed by implantation of an AUS or male sling when bladder neck is stable is essential to achieve a satisfactory urinary continence outcome.

Copyright @ 2016 S. Karger AG, Basel

\section{Introduction}

Bladder neck contracture (BNC) and post prostatectomy incontinence (PPI) are well known complications after radical prostatectomy (RP). Terminology of BNC can be confusing. In the scientific literature this entity of post prostatectomy complication is more commonly 


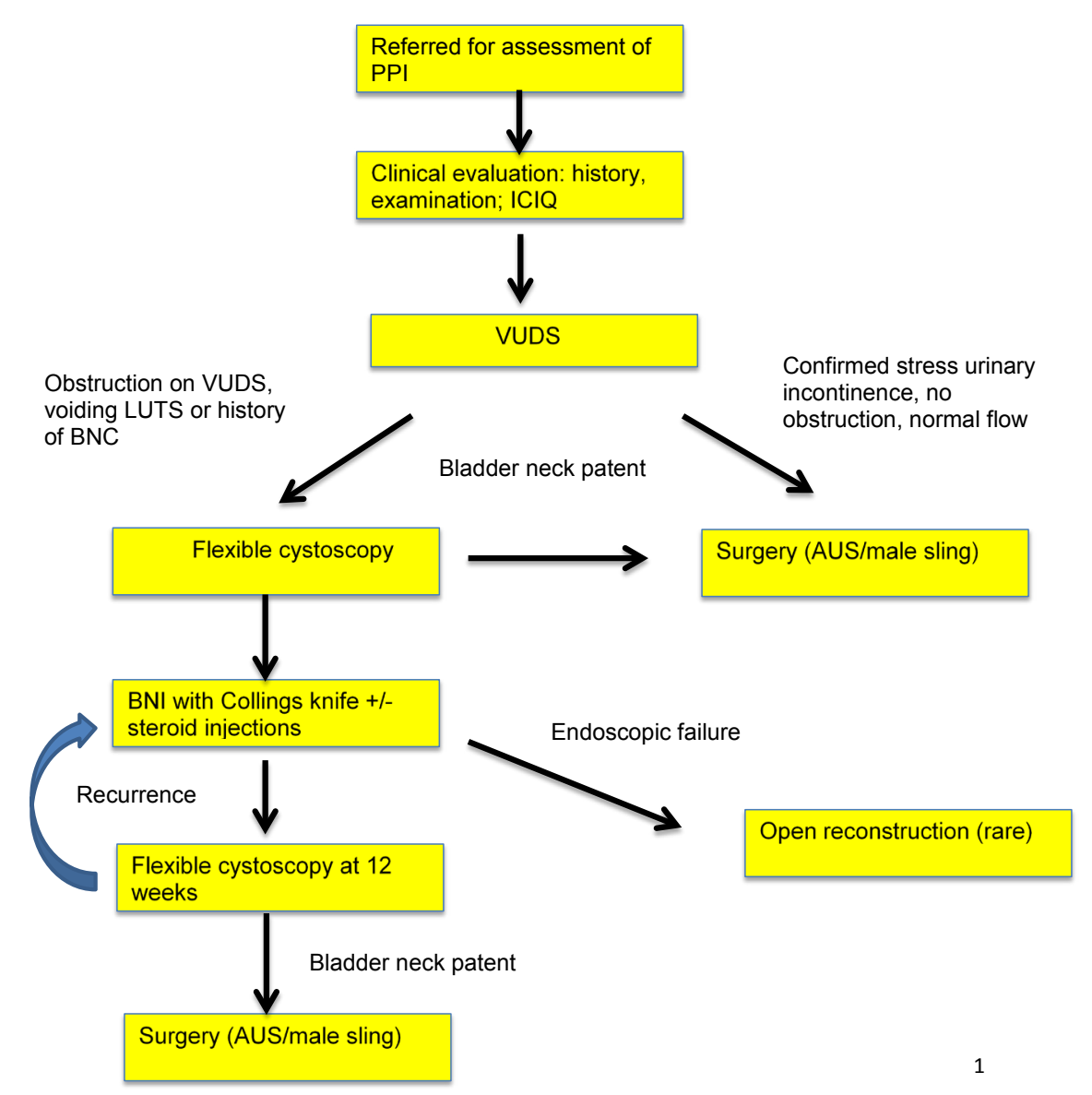

Fig. 1. Our approach to management of PPI with concomitant BNC (Thomas King and Y. Zaki Almallah, "Post-Radical-Prostatectomy Urinary Incontinence: The Management of Concomitant Bladder Neck Contracture", DOI: 10.1155/2012/295798.

known as BNC, although it should be referred to as vesicourethral stenosis as the bladder neck simply does not exist after radical prostatectomy. BNC or sphincteric stricture is defined as a narrowing of the vesicourethral anastomosis [1] and is generally defined as the inability to pass a flexible 15-17 Fr cystoscope though the anastomotic site $[2,3]$. The incidence of BNC varies in the literature from 0.45 to $17.5 \%$ in open RP and $0-3 \%$ in laparoscopic RP [2]. The incidence rate of PPI in these patients with concomitant BNC ranges 1-47\% [4] and $5 \%$ will require placement of either an artificial urinary sphincter (AUS) or a male sling [5].

The management of post RP BNC with concomitant PPI remains a challenge for urologists. There are various methods described in the literature though a consensus on the best treatment is yet to be reached. In our tertiary referral centre with a catchment area of over 8 million, a one-stop PPI service was set up in our institution in 2004 with both in-house and regional referrals [6]. The goal of this paper is to review our results and to present our experience in the management of $\mathrm{BNC}$ with concomitant PPI. We will also provide our recommendations based on the updated literature.

\section{Materials and Methods}

Patients referred to the service between January 2010 and June 2015 with cystoscopy diagnosed BNC and concomitant PPI were identified and the data reviewed retrospectively.

Rigid cystoscopy and deep Colling's endoscopic bladder neck incision (BNI) were performed on this group of patients. A follow-up flexible cystoscopy was then performed at 3 months to 
Table 1. Patient characteristics and preoperative parameters

\begin{tabular}{ll}
\hline Variable & Value \\
\hline Patients (n) & 37 \\
Mean age ( years) & $68(59-77)$ \\
Mean BMI $\left(\mathrm{kg} / \mathrm{m}^{2}\right)$ & $31(21-41)$ \\
Comorbidities (n, \%) & $14(37.8)$ \\
$\quad$ Hypertension & $1(2.7)$ \\
$\quad$ Diabetes & $7(18.9)$ \\
$\quad$ Ischemic heart disease & $1(2.7)$ \\
Smoking (n, \%) & $25(67.6)$ \\
RP approach (n, \%) & $12(32.4)$ \\
$\quad$ Open & $14(37.8)$ \\
$\quad$ Laparoscopic & \\
$\quad$ Radiotherapy & \\
\hline
\end{tabular}

assess for stability of the vescourethral anastomosis. A successful $\mathrm{BNC}$ therapy is achieved if the anastomosis remains stable. A second surgery was then performed to reinstate urinary continence with either an AUS or a male sling. The decision on either modality was made based on the continence level. Recurrent BNC at 3 months follow-up was treated with a repeat BNI procedure (fig. 1).

Patient demographics collected include the age, body mass index (BMI) and presence of comorbidities. The approach to RP , history of radiotherapy, mode of presentation of the BNC, number and type of BNI procedures and incontinence surgery and the pre and post-operative International Consultation on Incontinence Questionnaire (ICIQ) scores were also collected. Success was defined as remaining socially dry with a maximum of one continence pad used per day.

This study was approved by the institution audit committee (audit approval number 12022) and patient information was collected and analyzed on a datasheet with patient identifiers removed as per patient confidentiality guidelines.

\section{Statistical Analysis}

Independent samples $t$-test was used to assess the correlations between age, radiotherapy and RP approach (laparoscopic vs. open) and number of BNI procedures. The correlation between BMI and number of BNI was assessed using the Pearson's Test of Linear Correlation. The results were presented with $95 \%$ confidence intervals and $\mathrm{p}$ values. The number of BNI procedures performed was used as a marker of the level of complexity and severity of the patient's BNC status.

\section{Results}

Between January 2010 and June 2015, 341 patients were referred to the specialized PPI service. Thirty-seven patients $(10.8 \%)$ with $\mathrm{BNC}$ and concomitant PPI were identified and analyzed. The mean age was 68 years (range 59-77 years) and the mean BMI was $31 \mathrm{~kg} / \mathrm{m}^{2}$
Table 2. Number of patients with bladder neck incision procedures and number of patients with incontinence surgery

\begin{tabular}{ll}
\hline Variable & Value \\
\hline Patients with BNC and concomittant PPI & 37 \\
Patients underwent 1 BNI & $24(64.8 \%)$ \\
Patients underwent 2 BNI & $8(21.6 \%)$ \\
Patients underwent 2 or more BNI & $5(13.5 \%)$ \\
\hline
\end{tabular}

$\mathrm{BNI}=$ bladder neck incision; $\mathrm{PPI}=$ post prostatectomy incontinence

(range $21-41 \mathrm{~kg} / \mathrm{m}^{2}$ ). Twenty-five patients $(67.7 \%)$ had open RP and 12 patients (32.4\%) had laparoscopic RP. Fourteen patients $(37.8 \%)$ had adjuvant radiotherapy (table 1). Twenty-four (64.8\%) patients had one BNI procedure, $8(21.6 \%)$ patients had two procedures and $5(13.5 \%)$ patients had more than 2 procedures (table 2 ).

The mean waiting time from the last BNI procedure to incontinence surgery was 10.1 months (range 4-24). Among the $23(62.1 \%)$ patients who were successfully treated endoscopically with BNI, 21 patients $(91.3 \%)$ had an AUS implanted and 2 patients $(8.7 \%)$ had a male sling placed. Six patients $(42.9 \%)$ were still waiting for the incontinence surgery. Fourteen patients $(37.8 \%)$ did not undergo incontinence surgery. Among these patients, 1 patient passed away due to recurrence of prostate cancer, 2 patients $(14.2 \%)$ lost to follow up. Three patients $(21.4 \%)$ were not keen on incontinence surgery and were managed conservatively. Two patients $(14.3 \%)$ had recurrences of BNC post BNI procedure and were waiting for open reconstruction surgery.

The patient's age, BMI and approach of RP were not significantly related to the number of BNI procedures with p-values of $0.258,0.499$ and 0.773 respectively (fig. 2a-c). The presence of adjuvant radiotherapy correlated significantly to the number of BNI procedures $(\mathrm{p}$ $=0.039$ ) (fig. 2d).

The mean follow up period was 13.1 months (range 2-33 months). A successful outcome was achieved at follow up in 18/21 patients (85.7\%) who underwent an AUS procedure and in $1 / 2$ patients $(50 \%)$ who underwent a male sling procedure. The other patient who underwent a male sling procedure had to undergo insertion of AUS at a later date to persistent stress urinary incontinence (SUI).

The number of pads needed daily was significantly reduced from a mean of 5 pads (range 2-8 pads) pre-operatively to a mean of 0 pads (range $0-3$ ) post-operatively. 
a

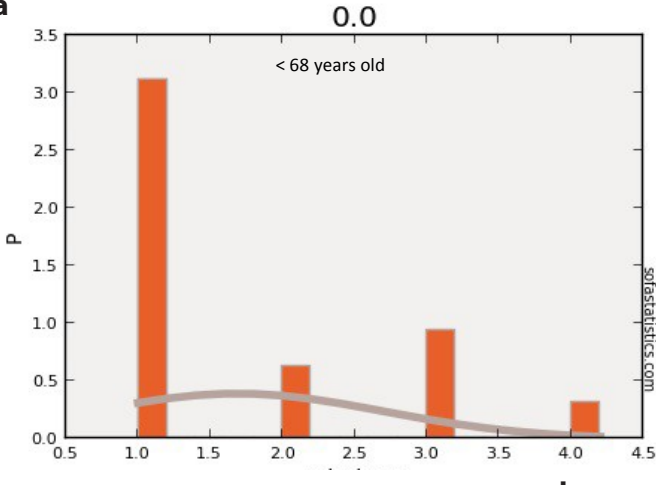

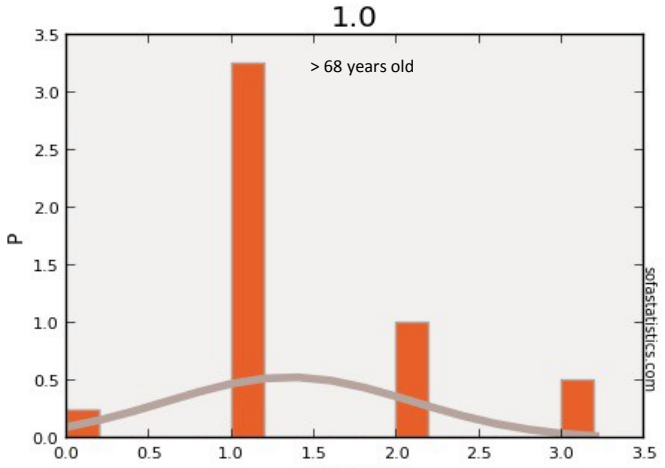
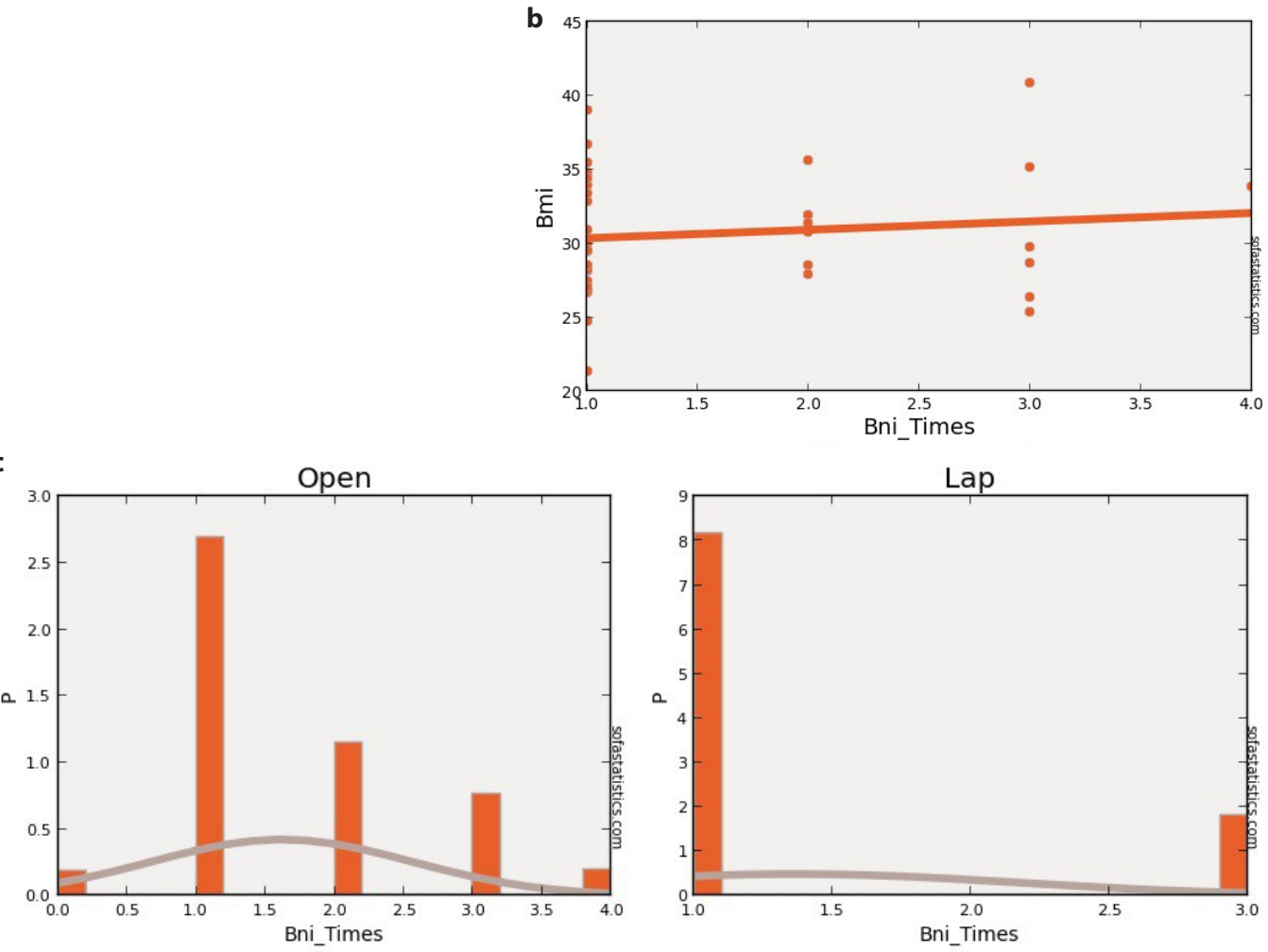

d

No RT
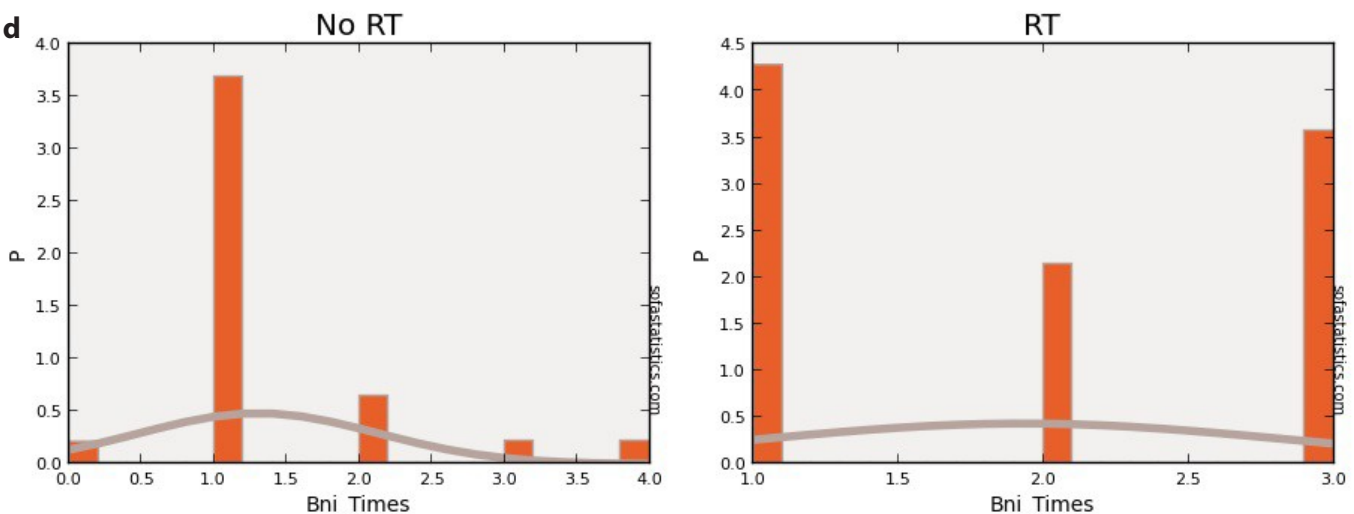

Fig. 2. a Results of Independent Samples $t$-test of average "BNI Times" for "Age $(>/<68)$ groups". b Results of Pearson's Test of Linear Correlation for "BNI Times" vs "BMI". c Results of Independent Samples $t$-test of average "BNI Times" for "Open" vs "Lap". d Results of Independent Samples $t$-test of average "BNI Times" for "No RT" vs. "RT". BNI = Bladder neck incision; BMI =body mass index; RT = radiotherapy. 
There was also improvement in the ICIQ score from a pre-operative mean score of 19 (range 15-21) to a postoperative mean score of 1.5 (range $0-14$ ).

Of the 21 patients who successfully underwent AUS implantation, 18 patients achieved successful outcomes. Of the remaining three patients, one patient had recurrent SUI due to urethral atrophy and two patients had revision of the AUS due to mechanical failure (Clavien-Dindo Classification grade IIIb). One of the two patients who underwent a revision of the AUS also subsequently developed recurrence of the BNC. This patient subsequently underwent a rigid cystoscopy and bladder neck dilatation with deactivation of AUS cuff and recovered without any complications (table 2) (Clavien-Dindo Classification grade IIIa). The patient who had recurrent SUI secondary to urethral atrophy opted for conservative management due to multiple co-morbidities and high risk for anesthesia.

\section{Discussion}

Post RP BNC is a well-established complication of $\mathrm{RP}$. BNC or sphincteric stricture is defined as a narrowing of the vesicourethral anastomosis [1] and is generally defined as the inability to pass a flexible $15-17$ Fr cystoscope through the vesicourethral anastomosis $[2,3]$. The risk factors for BNC include inadequate approximation of the vesicourethral anastomosis at the time of surgery, disruption of anastomosis by urinary extravasation or haematoma, excessive blood loss, obesity, prior radiation therapy, prior transurethral resection of prostate, smoking and older age group [7-9].

The surgical approach in RP also plays an important role in the development of BNC. The paper by Webb et al. [10] looked into the rates of BNC in patients undergoing open RP and robot assisted laparoscopic radical prostatectomy (RALP). No patient from the RALP group developed BNC whilst $9 \%$ of the open RP group developed a BNC. Better visualization during the vesicourethral anastomosis, a continuous suturing technique and overall reduced blood loss were possible reasons for the difference seen between patients undergoing open RP compared to laparoscopic RP or RALP [9-11].

Post RP BNC was diagnosed at a median of 4.7 months after surgery (range 1-15 months). The most common presenting complaints were slow urinary stream and urinary retention [12]. Other symptoms include recurrent urinary infection or an incidental diagnosis during cystoscopic investigation for PPI [13].

\section{Management of Post RP BNC}

The ideal management of post RP BNC should follow a step-wise pathway from simple to increasingly complex procedures. Urethral dilatation followed by clean intermittent catheterization (CIC) has been reported to have success rates ranging from 92 to $100 \%[14,15]$. In a study by Besarani et al. [15], a 100\% success rate with endoscopic dilatation was reported in 48 post RP patients with BNC. Nine patients (19\%) required a repeat dilatation and 5 required CIC. These patients all had subsequent stabilization of their BNC without need for further intervention. In patients whom simple dilatation fails, the $\mathrm{BNC}$ is treated with various endoscopic treatments that include balloon dilatation and BNI at the 3 and 9 o'clock positions using a Colling's knife or laser [7, 13].

In view of the recurrent nature of $\mathrm{BNC}$ after treatment, methods to prevent the recurrence of $\mathrm{BNC}$ have been advocated. In a paper by Eltahawy et al. [3], 24 patients with BNC underwent BNI using Holmium laser followed by injection of triamcinolone at the incision sites. Eighty-nine percent of patients had a well-healed and patent vesicourethral anastomosis after a mean follow up of 24 months. In another study by Vanni et al. [16], a retrospective review was performed on patients with recurrent BNC. Intralesional mitomycin C (0.3-0.4 $\mathrm{mg} / \mathrm{ml}$ at each incision site) was injected after urethrotomy. At a median follow up of 12 months, $72 \%$ of the patients had a patent bladder neck after 1 procedure, $17 \%$ had patency after 2 procedures and 1 patient achieved patency after 4 procedures.

Recurrent BNC despite multiple endoscopic interventions require a different treatment approach. In such situations, urethral stents or definitive reconstructive surgery have been advocated. A study by Milroy et al. [17] reported the use of urethral stents in patients with urethra strictures in a. At a mean follow up of 8 months post-stenting, ureteroscopy showed complete epithelization of the stent. Subsequent studies have reported satisfactory results in patients with BNC and concomitant PPI treated with UroLume ${ }^{\circledR}$ stents followed by synchronous or staged incontinence surgery $[18,19]$.

Definitive reconstructive surgery might be necessary in patients with recalcitrant BNC. In a paper by Borboroglu et al. [20], 467 post-RP patients were reviewed retrospectively and up to $27 \%$ of patients with $\mathrm{BNC}$ will be refractory to endoscopic interventions. In such patients with reasonable life expectancy who had failed repeated endoscopic interventions, definitive reconstruction surgery may be the only way to avoid lifelong catheteri- 
zation. Extensive perineal or abdominoperineal surgery with major reconstructive surgery may be undertaken to treat these patients with recalcitrant BNC s [21-23].

\section{Management of Post RP BNC with Concomitant PPI}

Post RP BNC is known to be an independent risk factor for PPI $[1,7]$. The presence of BNC may mask the severity of the underlying urinary incontinence that is due to sphincteric deficiency [13]. With that in mind, the $\mathrm{BNC}$ condition should be aggressively treated in the first instance before embarking on incontinence surgery.

Incontinence surgery should only be planned after stable vesicourethral anastomosis patency has been achieved. The rationale for this is the recurrent nature of $\mathrm{BNC}$ that will jeopardise the results of any incontinence surgery repair. Subsequent endoscopic interventions for BNC after incontinence surgery such as insertion of AUS carry a risk of damage to the device $[1,13]$.

Staged and synchronous approaches to the treatment of BNC with concomitant PPI have both been reported. There is however a lack of consensus on the duration necessary for the post-surgery stabilization of BNC prior to undertaking any staged incontinence surgery. Most studies on staged intervention reported waiting times ranging from 4 to 12 weeks $[2,7,13,24]$. Both the staged and synchronous approaches have its advantages and disadvantages (Supplementary table 2).

Urethral wall stents with subsequent insertion of AUS has shown promising results. In a study by Magera et al. [18], 25 patients with BNC after RP who underwent urethral stent and subsequent AUS insertion were identified. The impact on the quality of life as a result of PPI was analyzed using a self-administered, standardized questionnaire. With a median follow up of 2.9 years, $52 \%$ of patients achieved BNC stabilization with insertion of 1 urethral wall stent. Improvement in quality of life was noted in 23 patients $(92 \%)$ after subsequent insertion of AUS. In another similar study by Elliott et al. [19], 9 patients with recurrent BNC were treated with UroLume ${ }^{\circledR}$ stent across the contracture followed by staged AUS placement. After a mean follow up of 17.5 months, the mean pad per day usage decreased from 6.5 pre-AUS insertion to 0.7 post-AUS insertion. In this study, only two patients reported mild perineal discomfort and only one patient had a recurrent contracture requiring placement of a second overlapping stent. Overall, $89 \%$ of the patients were satisfied with the results.

Borawski et al. [25] also reported on their results of a combined approach with a UroLume ${ }^{\circledR}$ urethral stent placement with subsequent staged AUS placement. Forty

Bladder Neck Contracture patients who underwent the procedure were reviewed retrospectively. An average of 2.25 treatments for stent ingrowth was required per patient. Nine patients had AUS erosions and of which seven of them had also been treated for stent ingrowth. Although there is an increased risk of AUS erosions in those who had retreatment for stent ingrowth, it was not statistically significant. The authors concluded that reintervention in patients with urethral stents posed a dilemma in the presence of an existing AUS.

Brede et al. [2] reported on their continence outcomes after treatment of recalcitrant post RP BNC. In their study, patients underwent BNI followed by interval placement of an AUS or male sling after three to four months of stable BNC condition. Sixty-three patients with BNC were reviewed and $46(73 \%)$ of them had successful treatment of their BNC. Thirty-three patients subsequently underwent placement of an AUS or male sling with two failures reported. One patient required a cystectomy after multiple episodes of urethral erosions and one patient with persistent mild incontinence post-operatively was satisfied after a secondary sling procedure after placement of AUS. Five patients out of the 63 patients with BNC eventually required a permanent urinary diversion after repeated failed procedures for recurrent BNC. Despite the failures mentioned above, the authors were still able to achieve continence in $66 \%$ of the patients.

These papers highlighted the challenges in managing patients with concomitant BNC and PPI. The reconstructive options range from minimally invasive urethral stenting to open reconstructive surgery. However, there are limitations to these papers and these include the retrospective nature of the studies, small patient cohort (range 9-77) and the lack of long term follow up (range 11-37 months). These limitations affect the ability to draw representative consensus from the various studies. However, careful patient selection taking into account the expertise of each institution can provide promising results (success rate $66-92 \%$ ).

In our center, a specialized service has been set up for PPI patients since 2004. The aim of the service was to allow easy access to investigations such as video-urodynamics and also a consultant urologist with sub-specialisation interest and training in PPI surgery. From the time of set up, our service has seen a steady rise of both regional and in-house referrals for PPI.

The present study identified 341 patients who were referred to the specialized PPI service between January 2010 and June 2015. Among these patients, 37 patients $(10.8 \%)$ with BNC and concomitant PPI were identified and analyzed. 
The recalcitrant nature of the BNC was demonstrated in our study. Thirteen patients $(35.1 \%)$ underwent 2 or more BNI procedures. The mean waiting time from the last BNI procedure to incontinence surgery was 10.1 month. In our opinion, this should be interpreted cautiously as the waiting time is confounded by the United Kingdom National Healthcare System waiting time.

Our preferred approach to the treatment of post RP BNC with concomitant PPI is the staged approach. A decision on performing either modality of incontinence surgery would be decided after stabilisation of the vesicourethral anastomotic status demonstrated on flexible cystoscopy at 3 months after the last BNI procedure. This is very much driven by our patient population who are often referred to our tertiary centre after having undergone several procedures at the initial referring hospital. Our proposed algorithm in the treatment of post RP BNC and concomitant PPI is illustrated in fig. 1.

Our study results show that after a mean follow up of 13.1 months, successful final outcomes were achieved in $85.7 \%$ patients who underwent staged AUS surgery. The number of pads significantly reduced from a mean of 5 pads per pay to mean of 0 pads per day. ICIQ score also improved from mean score of 19 to mean of 1.5. Two patients had recurrent SUI due to mechanical failure. Interestingly both of the patients had radiotherapy and had underwent 2 or more BNI procedures prior to insertion of AUS. We postulated that recurrent episodes of silent infections due to the history of radiotherapy and multiple BNI procedures might have resulted in mechanical failure of the device.

\section{Radiotherapy}

The presence of previous radiotherapy affects to a large extent on the treatment of post prostatectomy BNC and PPI. The severity of urinary complications after radiotherapy will affect the outcome of PPI surgery. It was postulated that radiotherapy causes poor tissue healing, damage to the external sphincter as well as impairing bladder function. These reasons all contribute to higher rates of post-operative complications in patients with previous radiotherapy [2].

In a meta-analysis by Bates et al. [29] reporting on the complications following AUS placement in patients who had undergone RP and radiotherapy, the AUS revision rate was much higher in men who had RP and adjuvant radiotherapy compared to those who had surgery alone (RR of 1.56; 95\% CI 1.02-2.41).

The effect of radiotherapy on the treatment of BNC was also noted in our study. The recalcitrant nature of the $\mathrm{BNC}$ in some of our patients correlated significantly with the presence of radiotherapy ( $\mathrm{p}=0.039)$ (fig. $2 \mathrm{~d}$ ). A combination of a more severe and recalcitrant $\mathrm{BNC}$ with post radiotherapy overactive bladder symptoms clearly affect the outcomes of PPI surgery. However, these patients should not be denied the opportunity of PPI surgery. An individualized approach will be needed to achieve success in this patient group [30].

\section{Limitations of the Study}

Our study is a retrospective study and data was collected by sieving through our electronic database and patient's case notes. The follow up of these patients was rather short. We recognised that most recurrences of BNC occur in the long term. Nevertheless, this paper still provides outcomes for an intermediate follow up period.

Patients with post RP BNC and concomitant PPI poses a challenge to the urologist. The primary goal of treatment is to achieve urethral voiding, better continence outcome and improve quality of life. Aggressive $\mathrm{BNI}$ as the initial management for BNC is followed by a period of observation to ascertain vesicourethral anastomosis stability is essential. In our experience, subsequent second stage incontinence surgery with implantation of an AUS or male sling have achieved satisfactory urinary continence outcomes. 


\section{References}

1 Cox A, Herschorn S: Management of the incontinent patient with a sphincteric stricture following radical prostatectomy. Curr Opin Urol 2014;24:578-585.

2 Brede C, Angermeier K, Wood H: Continence outcomes after treatment of recalcitrant post prostatectomy bladder neck contracture and review of the literature. Urology 2014;83: 648-652.

3 Eltahawy E, Gur U, Virasoro R, Schlossberg SM, Jordan GH: Management of recurrent anastomotic stenosis following radical prostatectomy using holmium laser and steroid injection. BJU Int 2008;102:796-798.

4 Sacco E, Prayer-Galetti T, Pinto F, Sacco E, Prayer-Galetti T, Pinto F: Urinary incontinence after radical prostatectomy: incidence by definition, risk factors and temporal trend in a large series with a long-term follow-up. BJU Int 2006;97:1234-1241.

5 Nam RK, Herschorn S, Loblaw DA, Liu Y, Klotz LH, Carr LK, Kodama RT, Stanimirovic A, Venkateswaran V, Saskin R, Law CH, Urbach DR, Narod SA: Population based study of long-term rates of surgery for urinary incontinence after radical prostatectomy for prostate cancer. J Urol 2012;188:502-506.

6 Almallah Z, Grimsley SJ: A report of a regional service for post prostatectomy urinary incontinence: a model for best practice? Ther Adv Urol 2015;7:69-75.

7 Wein A, Kavoussi LR, Novick AC, Partin AW, Peters CA: Campbell-Walsh Urology, 10th ed. Saunders Elsevier, 2012.

8 Herschorn S, Elliott S, Coburn M, Wessells H, Zinman L: SIU/ICUD consultation on urethral strictures: posterior urethral stenosis after treatment of prostate cancer. Urology 2014;83(3 suppl):59-70.

9 Cho HJ, Jung TY, Kim DY, Byun SS, Kwon DD, Oh TH, Ko WJ, Yoo TK: Prevalence and risk factors of bladder neck contracture after radical prostatectomy. Korean J Urol 2013; 54:297-302.

10 Webb DR, Sethi K, Gee K: An analysis of the causes of bladder neck contracture after open and robot-assisted laparoscopic radical prostatectomy. BJU Int 2009;103:957-963.
11 Msezane LP, Reynolds WS, Gofrit ON, Shalhav AL, Zagaja GP, Zorn KC: Bladder neck contracture after robot-assisted laparoscopic radical prostatectomy: evaluation of incidence and risk factors and impact on urinary function. J Endourol 2008;22:377-384.

12 Breyer BN, McAninch JW: Management of recalcitrant bladder neck contracture after radical prostatectomy for prostate cancer. Endoscopic and open surgery. J Urol 2011;185: 390-391.

13 King T, Almallah YZ: Post radical-prostatectomy urinary incontinence: the management of concomitant bladder neck contracture. Adv Urol 2012;2012:295798.

14 Park R, Martin S, Goldberg JD, Lepor H: Anastomotic strictures following radical prostatectomy: insights into incidence, effectiveness of intervention, effect on continence, and factors predisposing to occurrence. Urology 2001;57:742-746.

15 Besarani D, Amoroso P, Kirby R: Bladder neck contracture after radical retropubic prostatectomy. BJU Int 2004;94:1245-1247.

16 Vanni AJ, Zinman LN, Buckley JC: Radial urethrotomy and intralesional mitomycin $\mathrm{C}$ for the management of recurrent bladder neck contractures. J Urol 2011;186:156-160.

17 Milroy EJ, Chapple CR, Cooper JE, Eldin A, Wallsten H, Seddon AM, Rowles PM: A new treatment for urethral strictures. Lancet 1988; 1:1424-1427.

18 Magera JS Jr, Inman BA, Elliott DS: Outcome analysis of urethral wall stent insertion with artificial urinary sphincter placement for severe recurrent bladder neck contracture following radical prostatectomy. Urol 2009;181: 1236-1241

19 Elliott DS, Boone TB: Combined stent and artificial urinary sphincter for management of severe recurrent bladder neck contracture and stress incontinence after prostatectomy: a long-term evaluation. J Urol 2001;165:413415.

20 Borboroglu PG, Sands JP, Roberts JL, Amling CL: Risk factors for vesicourethral anastomotic stricture after radical prostatectomy. Urology 2000;56:96-100.
21 Theodoros C, Katsifotis C, Stournaras P, Moutzouris G, Katsoulis A, Floratos D: Abdomino-perineal repair of recurrent and complex bladder neck-prostatic urethra contractures. Eur Urol 2000;38:734-740.

22 Wessells H, Morey AF, McAninch JW: Obliterative vesicourethral strictures following radical prostatectomy for prostate cancer: reconstructive armamentarium. J Urol 1998; 160:1373-1375.

23 Westney OL: Salvage surgery for bladder outlet obstruction after prostatectomy or cystectomy. Curr Opin Urol 2008;18:570-574.

24 Anger JT, Raj GV, Delvecchio FC, Webster GD: Anastomotic contracture and incontinence after radical prostatectomy: a graded approach to management. J Urol 2005;173:1143-1146.

25 Borawski K, Webster G, Durham NC: Long term consequences in the management of the devastated, obstructed outlet using combined UroLume stent subsequent artificial urinary sphincter placement. J Urology 2010;183(4 suppl):e427.

26 Mark S, Pérez LM, Webster GD: Synchronous management of anastomotic contracture and stress urinary incontinence following radical prostatectomy. J Urol 1994;151:1202-1204.

27 Ventimiglia B, Tsirgiotis A, Fanzone I, Coco T, Privitera S: Urinary incontinence after radical prostatectomy. Neurophysiological and urodynamic diagnosis. Urologia 2011;78:8285.

28 Leach GE, Trockman B, Wong A, Hamilton J, Haab F, Zimmern PE: Post-prostatectomy incontinence: urodynamic findings and treatment outcomes. J Urol 1996;155:12561259.

29 Bates AS, Martin RM, Terry TR: Complications following artificial urinary sphincter placement after radical prostatectomy and radiotherapy: a meta-analysis. BJU Int 2015; 116:623-633.

30 Thiruchelvam N, Cruz F, Kirby M, Tubaro A, Chapple CR, Sievert KD: A review of detrusor overactivity and the overactive bladder after radical prostate cancer treatment. BJU Int 2015;116:853-861. 